\title{
Menerapkan Kesabaran Menurut Kitab Amsal dalam Mengajar Sekolah Minggu
}

\author{
Nelly \\ Sekolah Tinggi Alkitab Jember, Jember, Jawa Timur, Indonesia \\ jbcnelly@yahoo.co.id
}

\begin{abstract}
The Sunday School Service is a part of church service that requires characteristics of patience in addition to the ability and expertise in teaching. Patience in teaching children is the key to being able to effectively serve as a Sunday School teacher. This article aims to describe the concept of patience in Proverbs. By using the descriptive analysis method in Proverbs, the conclusion is that as a Sunday School teacher a slow ability to anger is needed.
\end{abstract}

Keywords: church service; Sunday school; Sunday school teacher; patience; patient

\begin{abstract}
Abstrak
Pelayanan Sekolah Minggu merupakan bagian pelayanan dalam gereja yang membutuhkan karakteristik sabar selain kemampuan dan keahlian dalam mengajar. Kesaabaran dalam mengajar anak-anak merupakan kunci untuk dapat melakukan pelayanan sebagai guru Sekolah Minggu secara efektif. Artikel ini bertujuan untuk mendeskripsikan konsep kesabaran dalam kitab Amsal. Dengan menggunakan metode analisis deskriptif pada kitab Amsal, maka diperoleh kesimpulan, bahwa sebagai seorang guru Sekolah Minggu dibutuhkan kemampuan lamban untuk marah.
\end{abstract}

Kata kunci: guru Sekolah Minggu; kesabaran; pelayanan gereja; sabar; Sekolah Minggu

\section{PENDAHULUAN}

Di era globalisasi dan semakin berkembangnya teknologi informasi membuat semua serba mudah dan cepat. Di satu sisi hal ini sangat menolong segala aktivitas manusia, sementara di sisi lain muncul gaya hidup egosentris yang hanya berpusat pada diri sendiri, tidak mempedulikan sesama bahkan lingkungan sekitar. Manusia berpacu dengan waktu sehingga segalanya serba terburu-buru. Akibatnya jika segala aktivitas dan kebutuhan manusia tidak terpenuhi maka dapat menimbulkan konflik dengan sesama; tidak sabar, marah, perselisihan, perpecahan bahkan tidak jarang terjadi pembunuhan.

Menurut penelitian yang diterbitkan oleh Journal of American Medical Association pada tahun 2003, dilaporkan bahwa orang yang tidak memelihara kesabaran pada usia 1830 tahun, memiliki kemungkinan besar mengalami tekanan darah tinggi di kemudian hari. Orang yang selalu dalam keadaan tidak sabar dan marah secara konstan dalam kondisi 
stres, tubuhnya akan bereaksi melepaskan hormon seperti adrenalin dan kortisol yang merespons situasi stres. Kandungan adrenalin dan kortisol yang tinggi akan menyebabkan gula darah tinggi dan tekanan darah tinggi. Hormon ini juga memicu tubuh untuk melepaskan lemak ke dalam aliran darah sehingga masuk ke arteri koroner. Arteri koroner adalah pembuluh darah yang membawa makanan kepada otot jantung. Hormon stres (adrenalin dan kortisol) yang tinggi dapat memicu platelet untuk membekukan darah di arteri koroner sehingga memperbesar risiko serangan jantung. Jadi begitu pentingnya memiliki sifat sabar dalam menghadapi segala situasi.

Dalam pelayananNya, Yesus, Sang Guru Agung, memberi teladan dalam hal kesabaran. Ketika menghadapi orang-orang Farisi yang ingin mencobaiNya (Mat. 19:1-12), tetap sabar dan tidak emosi ketika mengetahui salah seorang muridNya akan mengkhianatiNya (Mat. 26:21-25) dan juga ketika Ia mengajar murid-muridNya dan orang banyak. Belajar dari teladan yang diberikan Yesus, para pelayan Tuhan khususnya di bidang Sekolah Minggu pun dapat sabar ketika mengajar anak-anak, relasi antar guru, menghadapi pimpinan gereja serta orang tua anak. Artikel ini bertujuan untuk mendeskripsikan konsep sabar menurut Kitab Amsal, serta aplikasinya dalam pelayanan guru Sekolah Minggu.

Pelayanan guru Sekolah Minggu merupakan sebuah tanggung jawab yang penting dalam gereja, sehingga dibutuhkan karakteristik dan nilai-nilai kepribadian yang dapat melayani anak secara baik, selain kemampuan dan keahlian. Dalam penelitian Tanto Kristiono dan Deo Putra Perdana menyebutkan adanya berbagai hambatan dalam melayani Sekolah Minggu ${ }^{1}$, sehingga guru dituntut untuk dapat melayani secara kreatif. Artinya, dalam konteks pelayanan secara umum, seorang guru Sekolah Minggu juga dituntut untuk dapat mengaktualisasikan pelayanan sesuai karunianya. ${ }^{2}$ Pelayanan sekolah Minggu merupakan sebuah bentuk pelayanan yang membutuhkan karunia khusus dalam melakukannya, agar anak-anak yang dilayani dapat ditangani secara efektif.

Prinsip pelayanan Sekolah Minggu merupakan bagian dari penerapan pola pendidikan Kristiani yang dilakukan di gereja. Istilah sekolah setidaknya mengimplikasikan sebuah proses pendidikan terjadi di sana, antara guru dan anak didik. Mendidik anak-anak bukan hal yang mudah, terlebih membuat mereka mau mendengarkan dengan penuh ketaatan. Menurut Harls Evan R. Siahaan, Pendidikan Kristiani yang diberikan kepada anak-anak dalam konteks pelayanan Sekolah Minggu juga berupaya membangun sebuah sikap diri

\footnotetext{
${ }^{1}$ Tanto Kristiono and Deo Putra Perdana, "Hambatan Dan Pelayanan Guru Sekolah Minggu Di Gereja Kristen Jawa Jebres Surakarta,” Jurnal Teologi Gracia Deo 1, no. 2 (2019): 90-100, http://www.sttbaptisjkt.ac.id/e-journal/index.php/graciadeo/article/view/9.

${ }^{2}$ Harls Evan R. Siahaan, "Aktualisasi Pelayanan Karunia Di Era Digital," EPIGRAPHE: Jurnal Teologi dan Pelayanan Kristiani 1, no. 1 (2017): 23-38, www.stttorsina.ac.id/jurnal/index.php/epigraphe.
} 
dari anak-anak yang dengar-dengaran. ${ }^{3}$ Artikel tersebut menekankan goal dalam proses pendidikan yang berorientasi pada anak didik, termasuk jika prinsip ini diterapkan dalam mengajar Sekolah Minggu. Artikel ini memiliki orientasi yang berbeda, di mana dalam proses pendidikan tersebut guru harus memiliki sikap yang sabar dalam menangani anakanak yang diajarnya.

Penelitian ini memilki perbedaan dari beberapa penelitian sebelumnya, termasuk yang dilakukan oleh Siahaan, yang menekankan proses pendidikan pada hasil yang dicapai oleh murid atau anak didik. Sikap dan perilaku kesabaran dalam mengajar sekolah Minggu merupakan hal yang penting untuk diperhatikan guru-guru Sekolah Minggu. Penelitian ini mengusulkan untuk menerapkan konsep kesabaran dalam kitab Amsal bagi guru Sekolah Minggu.

\section{METODE PENELITIAN}

Ini merupakan penelitian kualitatif yang menggunakan metode analisis teks Alkitab dengan pendekatan hermeneutis pada kitab Amsal. Metode deskripsi digunakan untuk memperlihatkan beberapa konsep kesabaran dalam kitab Amsal. Dalam Kitab Amsal sifat sabar paling dipuji; karena sangat berharga dalam praktik hidup untuk menghindari perselisihan, juga dalam menertibkan perkara-perkara dunia dengan bijaksana, terutama jika terlibat dalam hal-hal yang menimbulkan amarah. Orang Kristen wajib menunjukkan kesabaran seperti kesabaran Allah, dalam hubungan satu sama lain (band: Mat. 18:26,29; 1 Kor. 13:4; Ef. 4:2). ${ }^{4}$

\section{Pengertian Sabar}

Kata "sabar" menggunakan Bahasa Ibrani erekh sedangkan Bahasa Yunani makrothumia. Kesabaran dalam Bahasa Yunani terdiri dari dua kata: makros, "panjang", dan thumos "temperamen", yang memberikan makna "kelunakan", "mau menanggung", "panjang sabar", "tabah", "tahan menderita." Juga termasuk dalam kata makrothumia ini kekuatan untuk menanggung aniaya dan perlakuan buruk. Menggambarkan orang yang memiliki kemampuan untuk membalas dendam, tetapi sebaliknya memilih untuk menahan diri. Dalam Kamus Umum Bahasa Indonesia, kata "sabar" berarti tahan menghadapi cobaan (tidak lekas marah, tidak lekas putus asa, tidak lekas patah hati); tabah; tenang; tidak tergesa-gesa; tidak terburu nafsu. ${ }^{5}$ Jadi "sabar" adalah lambat untuk marah dan dapat menahan diri.

\footnotetext{
${ }^{3}$ Harls Evan Rianto Siahaan, "Hikmat Sebagai Implikasi Pendidikan Kristiani Dalam Keluarga: Refleksi 1 Raja-Raja 3:1-15,” DUNAMIS (Jurnal Teologi dan Pendidikan Kristiani) Vol 1, no. 1 (2016): 15-30, www.sttintheos.ac.id/e-journal/index.php/dunamis.

${ }^{4}$ Ensiklopedi Alkitab Masa Kini Jilid II (Jakarta: Yayasan Komunikasi Bina Kasih, 2008), 335.

5“Sabar"; KBBI. Versi 1.1 CD-Rom.
} 


\section{Lambat untuk marah}

Amsal 14:29 berbunyi: "Orang yang sabar besar pengertiannya, tetapi siapa cepat

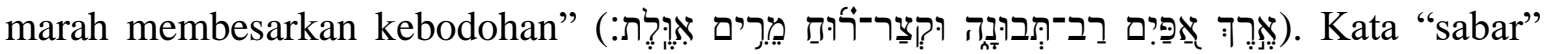
diterjemahkan oleh KJV "slow to wrath" (lambat gusar, marah, murka). Dalam NAS dan RSV diterjemahkan "slow to anger" sedangkan NIV diterjemahkan "patient". Dari perbedaan terjemahan, penulis menggunakan terjemahan "sabar" berarti "slow to anger". Kata "slow to anger" (lambat untuk marah) menggunaan Bahasa Ibrani (arek) adjective masculine singular construct.

Amsal 15:18 berbunyi: "Si pemarah membangkitkan pertengkaran, tetapi orang yang

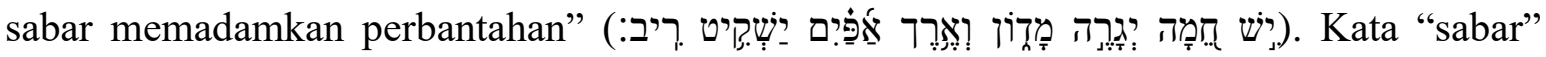
diterjemahkan oleh NIV "patient" sedangkan KJV, NAS, RSV diterjemahkan "slow to anger". Dari perbedaan terjemahan, penulis menggunakan terjemahan "slow to anger" (lambat untuk marah). Kata "sabar" menggunakan Bahasa Ibrani אָר (arek) adjective masculine singular construct.

Amsal 16:32: "Orang yang sabar melebihi seorang pahlawan, orang yang menguasai

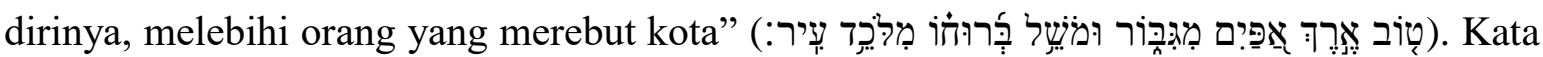
"sabar" diterjemahkan oleh NIV "patient” sedangkan KJV, NAS, RSV diterjemahkan "slow to anger" (lambat untuk marah). Penulis menggunakan terjemahan "slow to anger" (lambat untuk marah). Kata "sabar" menggunakan Bahasa Ibrani אָ adjective masculine singular construct.

Amsal 19:11, "Akal budi membuat seseorang panjang sabar dan orang itu dipuji karena

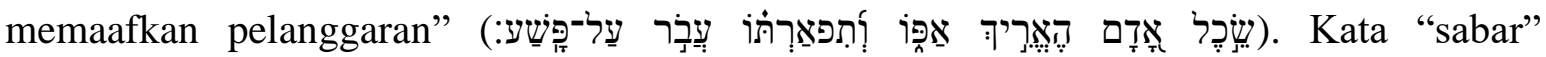
diterjemahkan oleh KJV “deferreth his anger” sedangkan NAS, RSV diterjemahkan "slow to anger" dan NIV diterjemahkan "patience". Perbedaan terjemahan ini, penulis menggunakan terjemahan "slow to anger" (lambat untuk marah). Kata "sabar" menggunakan Bahasa Ibrani הקאריך (he’érîk) berasal dari kata ארך verb hiphil perfect 3rd person masculine singular.

Dari keempat ayat tersebut di atas dapat disimpulkan bahwa sabar adalah sifat yang dimiliki atau melekat secara aktif dalam diri seseorang.

\section{Menahan Nafsu}

Amsal 25;15, "Dengan kesabaran seorang penguasa dapat diyakinkan dan lidah lembut

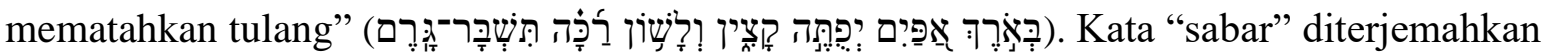
oleh KJV "forbearing" (sabar) dan oleh NAS diterjemahkan "forbearance" (kesabaran, penahanan (nafsu). Sedangkan oleh NIV dan RSV diterjemahkan "patience" (kesabaran). Penulis menggunakan terjemahan "kesabaran" yang menekankan pada "penahanan nafsu". Kata "sabar" menggunakan Bahasa Ibrani ארָך (orek) noun common masculine singular 
construct. Kata ארֶק (orek) adalah noun (kata benda) yang berposisi sebagai subyek yang memimpin ayat yang bersangkutan. Karena (orek) menggunakan maskulin tunggal ארֶך: (orek) hanya berkaitan dengan subyek tunggal. Jadi "sabar" merupakan ciri khas yang khusus dimiliki oleh subyek (seseorang) yang bersifat maskulin. Orang yang sabar adalah mampu menahan nafsu untuk marah.

\section{Kesabaran adalah Karakter Allah}

Salah satu karakter Allah adalah sabar (Nah. 1:7; Maz. 145:8). Sifat ini bukanlah kepasifan, tapi penguasaan atau pengekangan ataupun pengendalian diri Allah menghadapi perlawanan dan hal-hal lain yg menimbulkan amarah-Nya. Sifat ini hampir selalu dikaitkan dengan sifat kasih sayang dan kemurahan Allah terhadap orang berdosa dan pemberontak, yang sebenarnya patut kena murka-Nya. ${ }^{6}$ Paulus mengajarkan agar orang Kristen mengejar kesabaran selain keadilan, ibadah, kesetiaan, kasih dan kelembutan karena kesabaran adalah salah satu sifat dari Allah.

Allah itu panjang sabar, sudi mengampuni, menyesal karena hukumanNya atau malapetaka yang hendak didatangkanNya, penyayang dan pengasih. Kasih setiaNya berlimpah-limpah, tetapi Ia tidak sekali-kali membebaskan dari hukuman orang yang bersalah (Kel. 3:6; Bil. 14:1; Neh. 9:17; Mzm. 86:15; 103:8; Y1. 2:13; Yn. 4:2; Nah. 1:3).

Apakah Allah itu kurang sabar? (Mik. 2:7). Dalam 1 Petrus 3:20 dikatakan bahwa Allah tetap menanti dengan sabar (makrothumia, kesabaran, kelapangan hati, ketekunan, ketahanan) pada zaman Nuh untuk menunggu orang bertobat, walau ternyata hanya delapan orang. Sampai saat ini pun Ia sabar (makrothumeo, bersabar) terhadap kamu, karena Ia menghendaki supaya jangan ada yang binasa, melainkan supaya semua orang berbalik dan bertobat (2 Pet. 3:9). Pada bagian lain juga dikatakan, "Maukah engkau menganggap sepi kekayaan kemurahanNya, kesabaranNya (anoche, penangguhan/penundaan hukuman Allah) dan kelapangan hatiNya (makrothumia)? Tidakkah engkau tahu, maksud kemurahan Allah ialah menuntun engkau kepada pertobatan?” (Rm. 2:4). “Anggaplah kesabaran Tuhan kita sebagai kesempatan bagimu untuk beroleh selamat" (2Pet. 3:15).

Yesus Kristus menunjukkan kesabaranNya dengan mengasihi orang yang paling berdosa seperti Paulus, agar mendapat hidup yang kekal (1 Tim. 1:16). Yesus telah membiarkan dosa-dosanya pada masa kesabaranNya (Rm. 3:25). Jadi sabar adalah salah satu dari karakter Allah. Karena kesabaranNya, maka manusia dapat berbalik dari dosa.

\section{PEMBAHASAN}

Guru Sekolah Minggu adalah bagian penting dari pelayanan pendidikan/pengajaran dalam gereja. Pentingnya pelayanan pendidikan/pengajaran dalam gereja mengacu pada hal: merupakan hal yang diajarkan dan diteladankan oleh Tuhan Yesus Kristus; Injil harus

\footnotetext{
${ }^{6}$ Ensiklopedi Alkitab Masa Kini Jilid II (Jakarta: Yayasan Komunikasi Bina Kasih, 2008), 335.
} 
diajarkan; kunci pertumbuhan gereja, baik secara kualitas maupun kuantitas; jemaat membutuhkan pelayanan pengajaran.

Tantangan zaman menuntut gereja kuat dalam pelayanan pengajaran. Untuk itu guru Sekolah Minggu sebagai salah satu komponen dalam pelayanan pendidikan dalam gereja, sangatlah dibutuhkan. Keberhasilan pelayanan pendidikan dan pengajaran bagi anak sangat ditentukan oleh guru Sekolah Minggu yang baik dan memiliki kompetensi yang dibutuhkan.

Pelayanan di bidang Sekolah Minggu tidaklah mudah. Selain kompetensi teologis dan pedagogis, yang tidak kalah penting adalah kompetensi spiritual/moral. Seorang guru Sekolah Minggu bukan hanya dituntut mampu mengajarkan Alkitab yang adalah firman Tuhan tetapi keteladanan hidup pun harus dapat dilihat/diteladani oleh anak didiknya. Salah satu hal yang penting yaitu dalam hal kesabaran. Seperti yang disebutkan dalam Kitab Amsal bahwa sabar memiliki arti lambat untuk marah dan menahan nafsu.

Setiap anak memiliki banyak perbedaan; di antaranya karakter, usia, latar belakang keluarga, pendidikan, gaya belajar dan lainnya. Dengan adanya perbedaan maka pelayanan di Sekolah Minggu sangatlah dibutuhkan kesabaran. Anak yang memiliki karakter kurang baik biasanya membuat masalah dalam kelas, susah diatur. Jika seorang guru tidak sabar, cepat marah, maka tentulah akan stres menghadapi anak yang demikian.

Jikalau Tuhan memberi kepercayaan untuk menjadi seorang guru, haruslah disadari bahwa kita sedang dijadikan arsitek jiwa bagi orang lain, kita harus merencanakan bagaimana menjadikan mereka menjadi orang-orang yang akan dibentuk. Seseorang yang masih kanak-kanak akan sangat mudah untuk dibentuk. Mereka memiliki kecenderungan

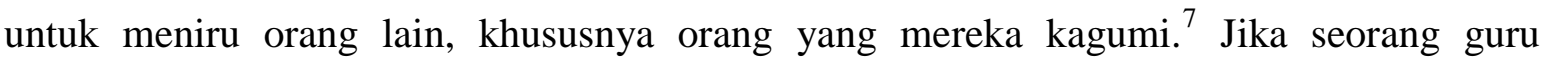
memahami akan hal ini, maka tentulah akan menjadi seorang guru yang disenangi anak didiknya, sehingga mereka akan dengan mudah diarahkan menjadi pribadi yang serupa dengan Kristus.

Menurut Paulus Lie, ada tujuh hal yang harus dimiliki oleh seorang guru Sekolah Minggu $^{8}$, yakni: meyakini panggilannya sebagai guru penuh waktu, memahami visi dan misinya sebagai guru, hidup dipimpin dan mengandalkan Roh Kudus, rela mempersembahkan totalitas dirinya bagi pelayanan anak, doa syafaat bagi anak, hadir dan mengajar dengan cinta, menjadi seorang gembala bagi anak-anaknya. Berdasarkan tujuh hal di atas maka tidak ada alasan bagi guru Sekolah Minggu untuk tidak sabar dalam menghadapi anak didiknya, bagaimana pun karakter mereka.

\footnotetext{
${ }^{7}$ Stephen Tong, Seni Membentuk Karakter Kristen (Surabaya: Momentum, 2010), 37.

${ }^{8}$ Paulus Lie, Mereformasi Sekolah Minggu (Yogyakarta: ANDI, 2009), 94.
} 
Anak-anak yang berperilaku kurang baik perlu mendapatkan perhatian khusus. Mungkin saja di rumah mereka kurang mendapatkan perhatian dan kasih sayang dari orang tua atau karena pengaruh pergaulan dengan teman yang tidak seiman di sekolah atau tempat bermain akibatnya, di kelas Sekolah Minggu mereka membuat keributan, tidak fokus pada saat guru memberi pelajaran Alkitab, malas atau tidak mau terlibat dalam aktivitas kelas.

Seorang guru haruslah mengetahui dan memahami bahwa anak memiliki banyak perbedaan. Usia, jenis kelamin, kebiasaan, pola belajar, pendidikan, latar belakang keluarga dan lain-lain, akan mempengaruhi tingkah laku. Dengan memiliki pengetahuan akan hal ini maka seorang guru Sekolah Minggu akan mampu untuk menahan nafsu untuk marah ketika menghadapi anak didiknya. Mendidik anak dengan sabar ketika puji-pujian, doa, firman Tuhan, membawa persembahan, ketika melakukan aktivitas di kelas setelah mendengarkan firman Tuhan.

Bukan hanya dalam menghadapi anak didik tetapi diperlukan juga kesabaran dalam menghadapi rekan sepelayanan yaitu sesama guru Sekolah Minggu. Setiap guru memiliki banyak perbedaan; karakter, metode mengajar, pengetahuan dan pemahaman Alkitab. Dalam menghadapi perbedaan ini sangat diperlukan kesabaran sehingga tidak terjadi perselisihan, kekacauan tetapi pelayanan dapat berjalan dengan baik seturut kehendak Tuhan.

Kesabaran dalam hubungan dengan sesama harus sesuai dengan kesabaran (Yunani: hupomone) dalam menghadapi penderitaan dan cobaan (Rom 5:3; 1Kor. 13:7; Yak. 1:3; 5:7-11; Why. 13:10). Kesabaran yang menyerupai kesabaran Yesus ini (Ibr 12:1-3) adalah karunia ilahi (Rom 15:5; 2Tes. 3:5). Orang Kristen yang bertahan sampai akhir karena kesabarannya, akan selamat atau memperoleh hidupnya (Mrk. 13:13; Luk. 21:19; Why. 3:10). Sabar merupakan salah satu unsur dari buah Roh (Gal. 5:22).

Sifat sabar menunjukkan kualitas kepribadian yang dimiliki oleh seorang guru. Upaya peningkatan kualitas diri supaya guru dapat menunaikan tugas mengajar secara efektif itu sangat mendesak. Dalam dunia pendidikan, seorang guru atau dosen wajib memiliki kompetensi: kepribadian, profesional, sosial dan pedagodis. Dalam konteks komunitas umat Tuhan, baik di gereja maupun dalam persekutuan di luarnya (parag ereja), panggilan untuk membenahi diri dalam kualitas keguruan sangatlah diperlukan.

B.S. Sidjabat mengatakan, untuk meningkatkan kualitas kepribadiannya, seorang pengajar Pendidikan Agama Kristen atau pengajar di bidang studi lainnya harus bertumbuh di dalam Kristus, dalam bimbingan Roh Tuhan serta memiliki konsep diri positif. ${ }^{9}$ Guru dipandang sebagai rekan sekerja Allah dalam proses memulihkan citra Allah yang hilang dalam manusia. Namun, mengingat keterbatasan kita sebagai manusia berdosa, maka

\footnotetext{
${ }^{9}$ B.S. Sidjabat, Mengajar Secara Profesional (Bandung: Kalam Hidup, 2014), 72-76.
} 
seorang guru sangat membuhkan pertolongan Tuhan untuk memiliki kualitas kepribadian yang baik sehingga guru dapat mendidik setiap muridnya untuk menjadi serupa dengan Kristus.

\section{KESIMPULAN}

Dari penjelasan di atas, ada dua hal yang dapat dipelajari dari Kitab Amsal, mengenai "sabar", yakni: lambat untuk marah dan menahan nafsu untuk marah. Sabar adalah sifat yang dimiliki atau melekat secara aktif dalam diri seseorang. Memang tidak mudah memiliki sifat sabar. Tetapi orang yang dipimpin oleh Roh Kudus pasti akan dimampukan untuk selalu bersabar. Salah satu karakter Allah adalah sabar. Sifat ini selalu dikaitkan dengan sifat kasih sayang dan kemurahan Allah terhadap orang berdosa dan pemberontak, yang sebenarnya patut kena murka-Nya. Belajar dari karakter Allah, maka sepatutnyalah seorang guru Sekolah Minggu dalam hidup dan pelayanannya juga memiliki karakter sabar, baik dalam menghadapi murid maupun relasinya dengan sesama. Syarat mutlak bagi seorang guru Sekolah Minggu adalah pengalaman kelahiran baru yang kemudian diikuti kehidupan yang suci. Guru Sekolah Minggu mempunyai lebih banyak kesempatan dibanding kebayakan orang untuk memenangkan jiwa-jiwa kepada Kristus karena Injil yang mereka ajarkan adalah pusat iman Kristen.

\section{REFERENSI}

Alkitab Terjemahan Baru. Jakarta: LAI, 2000.

Ensiklopedi Alkitab Masa Kini Jilid II. Jakarta: Yayasan Komunikasi Bina Kasih, 2008. Kristiono, Tanto, and Deo Putra Perdana. "Hambatan Dan Pelayanan Guru Sekolah Minggu

Di Gereja Kristen Jawa Jebres Surakarta.” Jurnal Teologi Gracia Deo 1, no. 2 (2019): 90-100. http://www.sttbaptisjkt.ac.id/e-journal/index.php/graciadeo/article/view/9.Lie, Paulus. Mereformasi Sekolah Minggu. Yogyakarta: ANDI, 2009.

Siahaan, Harls Evan R. "Aktualisasi Pelayanan Karunia Di Era Digital.” EPIGRAPHE:

Jurnal Teologi dan Pelayanan Kristiani 1, no. 1 (2017): 23-38.

www.stttorsina.ac.id/jurnal/index.php/epigraphe.

Siahaan, Harls Evan Rianto. "Hikmat Sebagai Implikasi Pendidikan Kristiani Dalam

Keluarga: Refleksi 1 Raja-Raja 3:1-15.” DUNAMIS (Jurnal Teologi dan Pendidikan

Kristiani) Vol 1, no. 1 (2016): 15-30. www.sttintheos.ac.id/e-

journal/index.php/dunamis.

Sidjabat, B.S. Mengajar Secara Profesional. Bandung: Kalam Hidup, 2014.

Tong, Stephen. Seni Membentuk Karakter Kristen. Surabaya: Momentum, 2010. 